\title{
PERUBAHAN SOSIAL MASYARAKAT ACEH JAYA PASCA GEMPA DAN TSUNAMI 2004
}

\author{
Akmal Saputra \\ Sosiologi, Fakultas Ilmu Sosial dan Ilmu Politik, Universitas Teuku Umar \\ email: akmalsaputra@utu.ac.id
}

\begin{abstract}
This paper explains the social changes of Aceh Jaya society after the earthquake and tsunami 2004. This paper focuses on three things: changes in religious, social and cultural life as well as see the efforts of Aceh Jaya government in responding to the changes. The purpose of this research is to disclose the changes that occurred after the earthquake and tsunami which become the evaluation material for the policy maker and the planner of the community development program. The theory used in this research is the theory of social change. The method used in this research is qualitative method. Research findings indicate that there has been a change in the religious, social and cultural life of the Aceh Jaya community as a result of community development programs. Some of its development programs have an impact on people's non-self-reliance and some have been infiltrated by aqidah silting efforts which will then affect the religious life of the Aceh Jaya people. Changes in society also occur due to contact or interaction with different cultures that lasted for long periods of time. The Government of Aceh Jaya has made efforts to restore society to the expected conditions in accordance with the values prevailing in the Aceh Jaya society
\end{abstract}

Key Words: Community Development, Social Change

\section{PENDAHULUAN}

Tulisan ini merupakan hasil penelitian pada akhir Desember 2013 yang mencoba untuk mengungkapkan bagaimana situasi sosial masyarakat pasca bencana alam gempa dan tsunami Desember 2004 di Aceh Jaya, tulisan ini fokus melihat pada perubahan sosial masyarakat. Penulis mencoba membongkar pada tiga aspek perubahan, yaitu perubahan pada kehidupan keagamaan, kehidupan sosial dan aspek budaya, kemudian apa upaya-upaya pemerintah Aceh Jaya dalam menanggapi persoalan perubahan-perubahan yang terjadi dalam kehidupan masyarakat. Jika melihat perubahan maka akan melihat pra, saat dan pasca. Tulisan ini sebagai salah satu bentuk evaluasi terhadap situasi sosial dan perubahan sosial pasca bencana alam dan pasca program pembangunan masyarakat yang dimotori oleh NGO (Non Goverment Organization) baik asing maupun lokal di Aceh Jaya.

Sebelum bencana alam gempa dan tsunami kehidupan masyarakat Aceh Jaya berjalan dengan normal, nilai-nilai kearifan lokal masih berjalan dengan baik, masyarakat belum terkontaminasi dengan budaya-budaya yang dianggap asing, masyarakat beraktivitas sesuai dengan keahlian masing-masing, baik sebagai petani, nelayan, pekebun, pedagang dan sebagian bekerja dilingkungan pemerintahan, namun pasca gempa dan tsunami masyarakat Aceh Jaya mengalami krisis dari berbagai sektor, kehilangan mata pencaharian, 
kehilangan tempat tinggal dan kehilangan terhadap berbagai akses terhadap sumber-sumber ekonomi, bahkan juga kehilangan anggota keluarga yang mereka cintai. Permasalahan ini yang kemudian mengakibatkan angka kemiskinan di Aceh Jaya menjadi meningkat. Aceh Jaya merupakan salah satu wilayah terparah yang mengalami dampak bencana, selain wilayah Banda Aceh, Aceh Besar dan Aceh Barat.

Hasil observasi di beberapa daerah lain di Aceh, pasca implementasi program-program pembangunan masyarakat yang dilakukan oleh NGO lokal maupun asing, akan menyisakan berbagai persoalan baru bagi masyarakat setempat yang kemudian dinamakan dengan bencana sosial. Salah satunya, pada masa tanggap darurat bencana masyarakat selalu mendapatkan bantuan untuk kebutuhan sehari-hari tanpa harus bekerja, hal inilah yang kemudian mengubah perilaku sosial masyarakat, dari masyarakat yang punya etos kerja yang tinggi menjadi masyarakat yang dimanjakan oleh bantuan (charity).

Pasca gempa dan tsunami, Aceh Jaya menjadi daerah yang sangat terbuka terhadap dunia luar, hampir semua masyarakat dunia internasional dan juga nasional dapat kita temukan di kabupaten Aceh Jaya, mereka datang melalui NGO dengan mengemban berbagai misi. Keterbukaan dan kontak terhadap dunia luar yang kemudian berpengaruh kepada situasi sosial masyarakat dan berdampak pada nilai-nilai adat, kearifan lokal dan tradisi sosial budaya masyarakat Aceh Jaya.

Berangkat dari situasi sosial yang ada, maka peneliti mencoba untuk membongkar dan mengungkapkan perubahan-perubahan pada masyarakat Aceh Jaya pasca gempa dan tsunami. Adapun yang menjadi alasan peneliti memilih lokasi di kabupaten Aceh Jaya adalah kabupaten Aceh Jaya merupakan salah satu kabupaten yang mengalami musibah bencana alam gempa tsunami yang dahsyat. Manfaat dari penelitian ini adalah pertama, menjadi bahan masukan bagi pemerintah yang akan mengambil kebijakan untuk proses pembangunan masyarakat, kedua, bermanfaat bagi NGO disetiap akan merancang dan merencanakan berbagai program-program pembangunan masyarakat, ketiga, bermanfaat bagi para akademisi dan peneliti berikutnya yang akan melaksanakan penelitian sebagai salah satu sumber data awal atau dokumen untuk menentukan penelitian berikutnya.

\section{TINJAUAN PUSTAKA}

Telah terdapat artikel yang mengulas tentang Budaya Gotong Royong Masyarakat Dalam Perubahan Sosial Saat Ini, tulisan ini menguraikan tiga isu pokok yaitu: pertama, gotong royong sebagai perasaan dari Panca Sila dan penerapannya dalam interaksi sosial kehidupan sehari-hari, kedua, gotong royong mengandung unsur-unsur modal sosial, ketiga, kondisi masyarakat kontemporer yang berada dalam situasi kekacauan sosial karena lemahnya 
penerapan nilai-nilai gotong royong dalam interaksi sosial. ${ }^{1}$ Artikel ini memiliki hubungan yang erat dengan topik yang akan peneliti kaji, peneliti juga akan melihat bagaimana nilai-nilai gotong royong kaitannya dengan sosial dan budaya pasca gempa dan tsunami di kabupaten Aceh Jaya.

Telah terdapat karya ilmiah sebelumnya yaitu skripsi yang di teliti oleh Ismaila Mahasiswa Jurusan PMI, Fakultas Dakwah IAIN Ar-Raniry yang berjudul "Pengaruh Gempa dan Tsunami Terhadap Kehidupan Beragama Masyarakat Kecamatan Teunom Kabupaten Aceh Jaya tahun 2008" penelitian ini fokus pada satu kecamatan dan kemudian juga fokus pada satu bidang saja, yaitu kehidupan beragama, sedangkan penelitian yang peneliti lakukan adalah pada tiga bidang, yaitu agama, sosial dan budaya kemudian fokus untuk satu wilayah yaitu Kabupaten Aceh Jaya.

\section{Perubahan Sosial}

Menurut Ogburn, perubahan sosial meliputi unsur unsur kebudayaan baik yang material maupun yang non-material. Ogburn menekankan bahwa adanya pengaruh besar unsur-unsur kebudayaan material terhadap unsurunsur non-material. ${ }^{2}$ Perubahan pola pikir, sikap dan tingkah laku manusia dipengaruhi oleh perubahan-perubahan kebudayaan yang bersifat material, misalnya kondisi-kondisi ekonomis, geografis, atau biologis yang merupakan unsur-unsur kebudayaan material yang kemudian menyebabkan terjadinya perubahan-perubahan pada aspek aspek kehidupan sosial lainnya. ${ }^{3}$ Menurut Gillin dan Gillin, perubahan sosial sebagai suatu variasi dari cara-cara hidup yang telah diterima, baik karena disebabkan oleh perubahan komposisi penduduk, kebudayaan material, kondisi geografis dan ideologi maupun karena adanya difusi ataupun penemuan-penemuan baru dalam masyarakat. ${ }^{4}$

\section{Penyebab Perubahan Sosial}

Menurut Soekanto, penyebab perubahan sosial yaitu: ${ }^{5}$ adanya penemuan-penemuan baru, bertambah atau berkurangnya penduduk, terjadinya pemberontakan atau revolusi dalam masyarakat, terjadinya pertentangan-pertentangan dalam masyarakat. Sedangkan faktor-faktor yang

1 Tadjudin Noer Effendi, Budaya Gotong Royong Masyarakat Dalam Perubahan Sosial Saat Ini, Vol 2, No 1 (2013). Jurnal Pemikiran Sosiologi. Departemen Sosiologi. Universitas Gadjah Mada.

2 Soekanto (1990) dalam Jelamu Ardu Marius. 2006. Kajian Analitik:Perubahan Sosial. Jurnal Penyuluhan. September 2006 ,Vol. 2, No. 2. Institut Pertanian Bogor. Hal. 126

3 Jelamu Ardu Marius. 2006. Kajian Analitik: Perubahan Sosial. Jurnal Penyuluhan. September 2006 ,Vol. 2, No. 2. Institut Pertanian Bogor. Hal. 126

4Soekanto (1990) dalam Jelamu Ardu Marius. 2006. Kajian Analitik:Perubahan Sosial. Jurnal Penyuluhan. September 2006 ,Vol. 2, No. 2. Institut Pertanian Bogor. Hal. 126.

5Soekanto (1981) dalam Juliana Lumitang, 2015. Pengaruh Perubahan Sosial Terhadap Kemajuan Pembangunan Masyarakat di Desa Tara-Tara I. e-journal "Acta Diurna" Volume IV. No.2. Hal.4. 
berasal dari luar masyarakat yaitu: sebab-sebab yang berasal dari lingkungan fisik yang ada di sekitar manusia dan peperangan dengan negara lain.

\section{METODE PENELITIAN}

Penelitian ini menggunakan metode penelitian kualitatif, dengan menggunakan teknik pengumpulan data, yaitu observasi, dokumentasi dan wawancara secara mendalam. Teknik yang digunakan dalam penelitian ini adalah teknik purposive. Teknik analisis data pada penelitian ini adalah reduksi data, display data dan verifikasi data. Adapun informan dalam penelitian ini adalah Kepala Dinas Sosial, Kepala Dinas Syariat Islam (Abdullah Sufi), Ketua MPU/Pimpinan Dayah Tanoh Anou dan Kepala Sekretariat MPU (Abati dan Hasyim), Pj Sekretariat MAA dan Staf Bagian Umum (Hj. Nur Ainah dan Rosmiati), Kepala KUA Kecamatan Teunom (Ismaila), tokoh masyarakat/tokoh Agama yang juga bertugas di Kemenag (Ismet), tokoh masyarakat/tokoh Agama Kecamatan Krueng Sabee (Tgk Ahmad, Tgk Azhari dan Tgk Rani).

\section{TEMUAN DAN PEMBAHASAN}

\section{a. Perubahan Kehidupan Di Bidang Keagamaan, Sosial Dan Budaya}

Pada masa tanggap darurat bencana, pengamalan dibidang keagamaan pada sebagian masyarakat di Aceh Jaya mulai berkurang dan berubah, dibandingkan sebelum bencana gempa dan tsunami. Kegiatan dakwah yang disampaikan oleh para Da'i diterima kurang baik, menurut pak ismet ${ }^{6}$, masyarakat Aceh Jaya pasca gempa dan tsunami sedang mengalami krisis dari berbagai aspek, masyarakat sedang mengalami kehilangan tempat tinggal, kehilangan keluarga dan kehilangan mata pencaharian, sehingga pengamalan di bidang keagamaan tidak berjalan dengan baik.

Pasca gempa dan tsunami, masyarakat terlalu cepat menerima sesuatu hal yang baru, terkadang tanpa ada proses filter terlebih dahulu, kondisi yang demikian tentu saja di manfaat oleh kelompok-kelompok yang ingin mendangkalkan aqidah umat Islam melalui program-program kemanusiaan. Banyak bukti-bukti dokumen (buku dan selebaran) yang ditemukan oleh tokoh masyarakat tentang misi pendangkalan aqidah terhadap umat Islam pasca gempa dan tsunami. Selain itu juga muncul kasus yang langka yaitu tentang tanah wakaf, tanah wakaf yang sebelumnya di wakafkan oleh orang tuanya untuk kebutuhan umat sebelum gempa dan tsunami, kemudian di gugat dan di tarik kembali oleh anak-anaknya yang masih hidup pasca gempa dan tsunami.

Ada beberapa kasus-kasus yang lain, 7 ada sekelompok orang yang datang se-olah-olah hendak menyampaikan pesan-pesan agama kepada anakanak di salah satu sekolah MTsN di Aceh Jaya, namun yang terjadi adalah

\footnotetext{
6 Wawancara dengan Pak Ismet/tokoh masyarakat tanggal 26 Oktober 2013.

7Wawancara dengan Pak Ismet/tokoh masyarakat, tanggal 26 Oktober 2013.
} 
mereka mencoba mengkelabui pesan-pesan agama, seolah-olah datang dari lembaga yang akan menyampaikan pesan-pesan agama atau dakwah Islam, namun justru yang terjadi adalah mereka mencoba mempengaruhi anak-anak melalui logika, misalnya anak-anak diajak bermain dengan cara diberikan permen dan mainan, contoh: jika anak-anak mengatakan tuhannya satu, maka permennya dapat satu, jika anak-anak mengatakan tuhannya dua, maka permennya dapat dua, jika mengatakan tiga, maka permennya dapat tiga, tetapi sebagian anak-anak ada yang ragu untuk mengatakan tuhannya tiga atau lebih, tetapi karena anak-anak mengharapkan permen, ya mereka menyampaikan banyak, biar mendapatkan permen lebih banyak.

Kasus yang lain lagi yaitu8: "kalian kan orang Islam, kenapa tidak disiplin?, jika kalian tidak disiplin berarti agama kalian tidak benar," contoh yang lain "jika kalian berbuat salah, berarti tuhan akan mengambil tindakan kan ?" kemudian dia memberi contoh sambil menendang meja, kembali bertanya kepada anak-anak "mana tuhan kalian ? kok tidak ada tindakan apaapa dari tuhan?". Kasus-kasus lainnya juga ditemukan berbagai selebaran dari NGO, mereka datang membawa bantuan logistik, namun sekaligus membawa misi pendangkalan aqidah terhadap umat Islam. Menurut penuturan tokoh masyarakat, mereka juga pernah akan melaksanakan kebaktian di daerah Setia Bakti dan Rigaih, namun mendapat penolakan dari tokoh-tokoh masyarakat yang ada di sana.

Diatas Peneliti telah mengungkap beberapa kasus yang peneliti dapatkan dilapangan, kasus-kasus ini peneliti sampaikan untuk menjadi bahan evaluasi bagi setiap pemangku kebijakan khususnya pemerintah Aceh Jaya, agar tidak kembali terjadi proses pendangkalan aqidah bagi masyarakat Aceh Jaya dan juga di di daerah-daerah yang lain. Pertanyaannya kemudian adalah mengapa ini bisa terjadi? Kemudian apa yang menyebabkan kehidupan keagamaan masyarakat Aceh Jaya mengalami perubahan pasca gempa dan tsunami?.

Pasca gempa dan tsunami ${ }^{9}$, sebagian masyarakat, termasuk tokoh Agama dan tokoh masyarakat pergi meninggalkan Aceh Jaya, karena kondisi tempat tinggal mereka yang sudah terkena dampak gempa dan tsunami, hal ini kemudian berdampak kepada masyarakat yang tinggal di barak-barak pengungsian, berkurangnya siraman-siraman rohani yang mereka terima dibarak-barak pengungsian, kondisi tempat tinggal yang tidak seperti biasa, dahulunya masyarakat tinggal di rumah masing-masing, namun sekarang tinggal di tenda atau barak pengungsian, kondisi kehilangan mata pencaharian. Berbagai persoalan ini kemudian menjadi sebuah peluang dan dimanfaatkan oleh kelompok-kelompok yang mempunyai misi misionaris dengan cara

\footnotetext{
8 Wawancara dengan Pak Ismet/tokoh masyarakat, tanggal 26 Oktober 2013.

9 Wawancara dengan Pak Abdullah Sufi/Kepala Dinas Syariat Islam, tanggal 23
} Oktober 2013. 
memberi bantuan untuk menarik simpati dan kemudian mereka mencoba untuk menjalankan misi-misi pendangkalan aqidah.

Berkurangnya pemahaman agama di dalam masyarakat di pengaruhi oleh kurangnya siraman-siraman rohani yang diberikan oleh tokoh-tokoh agama dan tokoh masyarakat, selain dipengaruhi oleh adanya upaya-upaya asing yang mencoba untuk mendangkalkan aqidah umat Islam. Persoalan lainnya mengapa pendangkalan aqidah ini bisa terjadi di Aceh Jaya, hal ini disebabkan oleh kondisi di Aceh Jaya pada saat itu sedang mengalami krisis, kondisi sedang tanggap darurat bencana, rumah dan tempat tinggal tidak ada, makanan terbatas, hal ini yang membuat para tokoh atau da'i menjadi terbatas dalam menyampaikan pesan-pesan agama dan selain ada penyusup yang datang ke Aceh Jaya untuk menyebarkan misi-misi pendangkalan aqidah melalui lembaga-lembaga kemanusiaan.

Pasca gempa dan tsunami, peneliti juga menemukan bagaimana perubahan perilaku yang terjadi pada sebagian masyarakat Aceh Jaya, peneliti beranggapan bahwa perubahan perilaku yang terjadi adalah akibat adanya kontak dengan budaya yang berbeda, sebagian pendatang tentu saja membawa budaya yang berbeda dengan masyarakat setempat, bahkan ada yang mengabaikan nilai-nilai agama dan nilai-nilai kearifan lokal setempat, hal ini terjadi karena kondisi masyarakat Aceh Jaya pada saat itu sangat heterogen dan sangat terbuka bagi siapapun untuk masuk ke wilayah kabupaten Aceh Jaya. Masyarakat dari berbagai negara dan daerah dengan mudah kita temukan di Aceh Jaya, mereka hadir dengan berbagai misi, salah satunya adalah misi kemanusiaan.

Sebelum bencana gempa dan tsunami pergaulan masyarakat masih dapat terkontrol melalui kontrol sosial masyarakat dan nilai-nilai kearifan lokal masih berjalan dengan baik selain kondisi masyarakat Aceh Jaya juga masih sangat homogen, kontak dengan budaya asing masih sangat terbatas. Perubahan perilaku masyarakat sangat mencolok terjadi pada masa tanggap darurat, rehabilitasi dan rekonstruksi Aceh Jaya, hal ini dikarenakan kontak dengan budaya asing dan proses interaksi dengan budaya yang berbeda menjadikan masyarakat terbiasa dengan kondisi tersebut dan kemudian berdampak kepada masyarakat Aceh Jaya pada umumnya.

Pasca gempa dan tsunami, persoalan yang paling mencolok terjadi perubahan adalah kehilangan nilai-nilai kegotongroyongan dan kebersamaan pada masyarakat, nilai-nilai itu menjadi pudar. Sebagai salah satu contoh, gotong royong untuk membersihkan lingkungan sangat sulit dilakukan dibandingkan sebelum gempa dan tsunami, mengapa ini dapat terjadi? masyarakat telah di manjakan dengan pola program cash for work, karena setiap kegiatan membersihkan lingkungan akan mendapatkan bayaran, sekalipun itu lingkungan atau gampong sendiri, sehingga masyarakat menjadi enggan untuk 
melaksanakan kegiatan membersihkan lingkungan dengan pola gotong royong yang sebelumnya telah ada pada masyarakat jauh sebelum gempa dan tsunami.

Nilai-nilai gotong royong merupakan salah satu peninggalan budaya bangsa yang tidak dimiliki oleh bangsa lain, nilai-nilai gotong-royong merupakan peninggalan budaya bangsa yang sangat berharga. Nilai-nilai gotong royong ini malah di belahan dunia yang lain sedang digalakkan untuk meningkat kegiatan kerjasama di masyarakat. Justru sangat disayangkan jika nilai-nilai gotong royong yang berasal dari negara kita, kemudian menjadi pudar dan bahkan hilang sama sekali. Lalu kemudian apa sesungguhnya yang menyebabnya nilai-nilai ini menjadi pudar dan hilang? Salah satu penyebabnya adalah dampak dari program-program pembangunan masyarakat pasca gempa dan tsunami yang terkadang tidak mendidik masyarakat untuk lebih mandiri seperti yang telah peneliti sebutkan diatas. Mengembalikan nilai-nilai ini ke kondisi semula dan semangat gotong royong di masyarakat tentu butuh waktu yang cukup panjang dan lama, nilai gotong royong merupakan salah satu bentuk kearifan lokal yang ada di Aceh Jaya dan salah satu peninggalan budaya bangsa yang paling berharga.

\section{b. Upaya-Upaya Pemerintah}

Kondisi perubahan yang terjadi di dalam masyarakat baik itu bidang agama, sosial dan budaya, adalah kenyataan yang terjadi di tengah-tengah masyarakat Aceh Jaya hari ini. penelti menilai pemerintah Aceh Jaya dalam hal ini tanggap terhadap kondisi yang telah terjadi, salah satu bentuk dari kepedulian pemerintah Aceh Jaya adalah membentuk majelis taklim mubahasah, manajemen dan kegiatannya dimotori oleh pemerintah Aceh Jaya. Majelis taklim mubahasah ini dilaksanakan 1 (satu) bulan sekali, pelaksanaan berpindah-pindah dari setiap kecamatan ke kecamatan yang lain, misalnya bulan ini di kecamatan Pasie Raya nanti selanjutnya menuju ke kecamatan yang lain, prosedurnya bupati akan mengirimkan surat kepada camat bahwa hari minggu terakhir bulan ini akan dilaksanakan majelis taklim mubahasah di kecamatan Pasie Raya, begitu juga pelaksanaan di kecamatan-kecamatan yang lain, tokoh-tokoh agama yang di kecamatan tersebut di undang untuk hadir pada kegiatan majelis taklim, materi yang disampaikan tentang fiqh, tauhid dan tasawuf dan kehidupan sosial masyarakat, mengenai jadwal pelaksanaannya mulai pukul 09.00 WIB hingga jam 15.00 WIB, materi akan disampaikan oleh 2 (dua) orang pemateri dan 2 (dua) orang pembantu pemateri, harapannya adalah dengan ada wadah yang seperti ini, tokoh-tokoh agama yang berada di kecamatan pelaksanaan bisa memberi/membagi ilmu ke pada masyarakat yang di kecamatan tersebut.

Untuk memudahkan kegiatannya majelis taklim ini, pemerintah juga menyediakan bus sekolah untuk membawa peserta dari kecamatan yang lain ke kecamatan yang sedang melaksanakan majelis taklim mubahasah, selain itu 
pemerintah juga menyediakan dana Rp. 250.000,- (Dua Ratus Lima Puluh Ribu Rupiah) per kecamatan untuk kebutuhan transportasi bus sekolah, kegiatannya biasanya dilaksanakan pada hari minggu, hal ini dilakukan untuk menghindari benturan penggunaan bus sekolah, program ini sedang berjalan satu tahun setengah, pemerintah Aceh Jaya juga menyediakan dana Rp.3.000.000,- (Tiga Juta Rupiah) untuk setiap pelaksanaan kegiatan ini, selanjut juga ada bantuan masyarakat untuk kebutuhan konsumsi pada pelaksanaan kegiatan majelis taklim, biasanya bantuan masyarakat ini gabungan dari beberapa gampong yang memberikan sumbangan konsumsi. Selain ada majelis taklim mubahasah, ada juga majelis taklim tauhid tasawuf pimpinan Syeikh Amran Wali, walaupun tidak banyak titiknya seperti mubahasah. Selain itu, untuk peningkatan kehidupan keagamaan juga dibentuk majelis-majelis taklim di tingkat kecamatan, mukim dan gampong, biasanya kegiatannya berjalan mingguan, misalnya 1 (satu) minggu sekali.

\section{KESIMPULAN}

Pada era global, perubahan-perubahan memang akan terus terjadi sesuai dengan perkembangan zaman, memang sangat sulit membendung perubahanperubahan yang terjadi dalam kehidupan masyarakat, teknologi terus berkembang, informasi begitu mudah diakses, kontak dengan budaya yang berbeda juga begitu mudah terjadi, namun nilai-nilai kearifan lokal harus terus dipertahankan agar tidak kehilangan identitas suatu bangsa.

Pada penelitian ini, peneliti melihat tiga hal perubahan yang terjadi pada masyarakat Aceh Jaya, yaitu perubahan kehidupan keagamaan, sosial dan budaya, perubahan secara jelas terjadi yang merupakan dampak dari programprogram pembangunan masyarakat pasca gempa dan tsunami. programprogam pembangunan masyarakat yang sebagiannya kurang tepat sasaran dan kurang mendidik masyarakat untuk lebih mandiri, selain itu sebagian programprogram pembangunan masyarakat juga tidak murni sebagai program kemanusiaan, namun telah disusupi oleh program-program terselubung (misi pendangkalan aqidah) yang berdampak pada perubahan kehidupan keagamaan masyarakat Aceh Jaya.

Perubahan-perubahan sosial dan budaya juga terjadi akibat kontak dan interaksi sosial dengan budaya yang berbeda dalam rentang waktu yang lama, proses rehabilitasi dan rekonstruksi berjalan dalam waktu yang lama di kabupaten Aceh Jaya dengan hadirnya berbagai suku dan bangsa di Kabupaten Aceh Jaya, sehingga lambat laun mempengaruhi kehidupan sosial dan budaya pada masyarakat di Kabupaten Aceh Jaya. Upaya-upaya pemerintah Aceh Jaya untuk mengembalikan masyarakat Aceh Jaya pada kondisi masyarakat yang agamis dan masyarakat yang menghargai nilai-nilai kearifan lokal telah dilakukan melalui kegiatan-kegiatan keagamaan dengan dibentuknya majelismajelis taklim untuk kembali memperkuat aqidah umat di kabupaten Aceh 
Jaya.

\section{Daftar Pustaka}

\section{Buku}

Edi Suharto. 2006. Membangun Masyarakat Memberdayakan Rakyat, Kajian Strategis Pembangunan kesejahteraan Sosial dan Pekerjaan Sosial. Bandung:Refika Aditama

Elly M.Setiadi dan Usman Kolip. 2011. Pengantar Sosiologi, Pemahaman Fakta dan Gejala Permasalahan Sosial: Teori, Aplikasi dan Pemecahannya. Jakarta: Kencana Prenadamedia Group.

Ismaila, 2008. Pengaruh Gempa dan Tsunami Terhadap Kehidupan Beragama Masyarakat Kecamatan Teunom Kabupaten Aceh Jaya"Banda Aceh: Fakultas Dakwah IAIN Ar-Raniry (skripsi tidak diterbitkan).

Jelamu Ardu Marius. 2006. Kajian Analitik:Perubahan Sosial. Jurnal Penyuluhan. September 2006 ,Vol. 2, No. 2. Institut Pertanian Bogor.

Juliana Lumitang, 2015. Pengaruh Perubahan Sosial Terhadap Kemajuan Pembangunan Masyarakat di Desa Tara-Tara I. e-journal "Acta Diurna" Volume IV. No.2.

M.Dzikron A.M. 2009. Tragedi Tsunami di Aceh, Bencana Alam atau Rekayasa?. Yogyakarta: (MT\&P) LAW FIRM.

No. 2. Institut Pertanian Bogor.

Piotr Sztompka. 2008, "Sosiologi Perubahan Sosial"Jakarta : Prenada

Rencana Aksi Nasional Pengurangan Resiko Bencana2006-2009, Kerjasama antara Kementerian Negara Perencanaan Pembangunan Nasional/Badan Perencanaan Pembangunan Nasional dengan Badan Koordinasi Nasional Penanganan Bencana di Dukung oleh UNDP. Perum Percetakan Negara RI. 2006

Soerjono Soekanto. 2010, Sosiologi Suatu Pengantar. Jakarta : PT.Raja Grafindo Persada

Sutrisno Hadi. 2000. Metodologi Penelitian. Yogyakarta: Andi Offset.

Tadjudin Noer Effendi, Budaya Gotong Royong Masyarakat Dalam Perubahan Sosial Saat Ini, Vol 2, No 1 (2013). Jurnal Pemikiran Sosiologi. Departemen Sosiologi. Universitas Gadjah Mada. 